\title{
A utilização da musicoterapia no tratamento de idosos diagnosticados com a doença
}

\section{de Alzheimer}

The use of music therapy in the treatment of elderly diagnosed with Alzheimer's disease

El uso de la musicoterapia en el tratamiento de ancianos diagnosticados con enfermedad de

\section{Alzheimer}

Recebido: 30/08/2021 | Revisado: 07/09/2021 |Aceito: 14/09/2021 | Publicado: 14/09/2021

Amanda Nunes da Silva Sousa

ORCID: https://orcid.org/0000-0002-8903-0905

Centro Universitário Fametro, Brasil

E-mail: Amanda.shopie936@gmail.com

Mônica Silva Saraiva

ORCID: https://orcid.org/0000-0002-7309-4808

Centro Universitário Fametro, Brasil

E-mail: s.s.monica.psi@gmail.com

Thaísa Vittória Ribeiro Machado

ORCID: https://orcid.org/0000-0002-6459-2450 Centro Universitário Fametro, Brasil E-mail: thaisavittoria@hotmail.com

Júlio César Pinto de Souza

ORCID: https://orcid.org/0000-0003-3622-1393 Centro Universitário Fametro, Brasil

E-mail: cmte01@yahoo.con.br

\begin{abstract}
Resumo
Este artigo apresenta o estudo sobre a doença de Alzheimer, uma patologia crônica e degenerativa que compromete as funções cognitivas, que levam a transtornos neuropsiquiátricos, bem como alteração no comportamento e como a musicoterapia pode melhorar a qualidade de vida dos idosos. O objetivo do construto é investigar os efeitos da utilização da musicoterapia aplicada no tratamento da doença de Alzheimer em idosos diagnosticados com a psicopatologia, devido a sua ação benéfica da terapia citada. Trata-se de uma revisão sistemática de procedimento bibliográfico e abordagem qualitativa. O levantamento dos dados foi realizado nas plataformas Capes, Pepsic e Scielo, sendo utilizados os descritores: Doença de Alzheimer, Idosos, Velhos, Música e Musicoterapia. Os resultados mostram que a musicoterapia, por atuar nas funções cognitivas, é de fato uma terapia alternativa funcional com fortes evidências terapêuticas capaz de gerar uma melhor qualidade de vida, uma vez que sua aplicação provou ser capaz de retardar os sintomas da doença, além de reestruturar memórias que haviam sido esquecidas.
\end{abstract}

Palavras-chave: Doença de Alzheimer; Idosos; Velhos; Musicoterapia.

\begin{abstract}
This article presents the study of Alzheimer's disease, a chronic and degenerative pathology that compromises cognitive functions, which lead to neuropsychiatric disorders, as well as behavioral changes and how music therapy can improve the quality of life of the elderly. The aim of the construct is to investigate the effects of using music therapy applied in the treatment of Alzheimer's disease in elderly people diagnosed with psychopathology, due to its beneficial action of the aforementioned therapy. This is a systematic review of bibliographic procedure and a qualitative approach. The data survey was carried out on the Capes, Pepsic and Scielo platforms, using the descriptors: Alzheimer's Disease, Elderly, Elderly, Music and Music Therapy. The results show that music therapy, by acting on cognitive functions, is in fact a functional alternative therapy with strong therapeutic evidence capable of generating a better quality of life, since its application proved to be able to delay the symptoms of the disease, in addition to restructure memories that had been forgotten.
\end{abstract}

Keywords: Alzheimer's disease; Elderly; Music therapy.

\section{Resumen}

Este artículo presenta el estudio de la enfermedad de Alzheimer, una patología crónica y degenerativa que compromete las funciones cognitivas, lo que conduce a trastornos neuropsiquiátricos, así como cambios de comportamiento y cómo la musicoterapia puede mejorar la calidad de vida de las personas mayores. El objetivo del constructo es investigar los efectos del uso de la musicoterapia aplicada en el tratamiento de la enfermedad de Alzheimer en personas mayores diagnosticadas de psicopatología, debido a su acción beneficiosa de la terapia 
mencionada. Se trata de una revisión sistemática del procedimiento bibliográfico y un enfoque cualitativo. La encuesta de datos se realizó en las plataformas Capes, Pepsic y Scielo, utilizando los descriptores: Enfermedad de Alzheimer, Anciano, Anciano, Música y Musicoterapia. Los resultados muestran que la musicoterapia, al actuar sobre las funciones cognitivas, es en realidad una terapia alternativa funcional con fuerte evidencia terapéutica capaz de generar una mejor calidad de vida, ya que su aplicación demostró ser capaz de retrasar los síntomas de la enfermedad, además para reestructurar recuerdos olvidados.

Palabras clave: Enfermedad de Alzheimer; Anciano; Musicoterapia.

\section{Introduçãa}

A musicoterapia é uma ciência recente e adotada como uma terapia alternativa para diversos contextos. Os primeiros estudos nessa área foram em 1944, na região de Michigan, nos Estados Unidos, os quais buscavam evidências científicas que provassem a eficiência da música enquanto intervenção terapêutica. Nesse sentido, o principal elemento da musicoterapia se dá por meio da música, pois através de diferentes instrumentos e elementos musicais, se fazem possível a comunicação, a expressão, a reabilitação e estimulação cognitiva do paciente (Barcelos, 2018).

Quando utilizada de maneira correta, a musicoterapia proporciona aos pacientes uma melhora significativa nas relações sociais, facilitando principalmente a expressão por meio da música, inferindo nas esferas físicas, sociais, mentais e emocionais do indivíduo. Quanto aos diversos benefícios da utilização da musicoterapia, pôde-se verificar através da literatura uma melhora significativa sobre a respiração, circulação sanguínea, estimulação da memória e alívio da dor advindas de distúrbios psicossomáticos, físicos ou emocionais. (Mendes et al., 2020).

Por atuar nas faculdades cognitivas, a musicoterapia se mostra uma terapia alternativa funcional e eficaz para o tratamento do Mal de Alzheimer, uma vez que a doença compromete algumas funções, afetando a memória e pode desenvolver diversos distúrbios cognitivos (Smith, 1999). A esse respeito, Sacks (2007) comenta que em casos de doenças de cunho neurológico, a música pode ser uma forte aliada com imenso poder terapêutico, levando-se em consideração que pacientes diagnosticados com Alzheimer tendem a responder de forma mais significativa, se comparado a outros métodos de intervenção terapêutica.

A partir da temática, foi estabelecido como objetivo primário desta pesquisa investigar o uso da musicoterapia no tratamento de idosos diagnosticados com Alzheimer. Os trabalhos de investigação foram conduzidos inicialmente com o levantamento das características acerca da doença e, em seguida, a apresentação dos efeitos da musicoterapia na saúde e por último abordou-se sobre o uso da musicoterapia no tratamento de idosos com Alzheimer.

Acredita-se que as contribuições dos estudos são inúmeras, pois os resultados oferecem conhecimento para a comunidade cientifica no que tange aos efeitos benéficos da musicoterapia aplicada aos idosos diagnosticados com Alzheimer, sendo uma técnica alternativa com resultados comprovados. A musicoterapia mostrou-se uma alternativa para lidar com os sinais e sintomas da doença, pois a mesma oferece maior qualidade de vida para os pacientes e seus familiares, uma vez que esse tipo de intervenção traz o paciente para dentro do seu tratamento, devolvendo a esse indivíduo o sentimento de pertencimento que havia perdido com o avanço da doença.

Desse modo, a pesquisa pode contribuir com a comunidade acadêmica e profissional, buscando divulgar a eficácia dessa ferramenta terapêutica, possibilitando assim, a exploração de seu uso no enfrentamento da doença, e ainda, agregar as demais pesquisas já existentes e/ou possibilitar o desdobramento de novos estudos que corroborem ou contraponham-se, dentro da temática.

\section{Metodologia}

Essa pesquisa foi uma revisão sistemática, de procedimento bibliográfico e abordagem qualitativa. A construção da revisão sistemática foi fundamentada no trabalho científico de Donato e Donato (2019) as quais argumentam que a revisão 
sistemática consiste em compilar os métodos explícitos que conduzem a pesquisa bibliográfica, avaliando criteriosamente os estudos individuais. As autoras ainda comentam que essa revisão consiste em uma metodologia abrangente, transparente e replicável, com a finalidade de avaliar a qualidade dos dados e sintetizar os seus resultados.

O procedimento bibliográfico buscou levantar os trabalhos acerca do tema publicados como livros, Trabalhos acadêmicos, artigos científicos e revistas eletrônicas (Gil et al., 2002). A abordagem qualitativa foi usada para buscar a compreensão profunda dos aspectos que envolvem a temática investigada (Ribeiro, 2008). Para Gomes e Gomes (2020, p. 6), esse tipo de pesquisa procura "descrever, decodificar, traduzir, construir e analisar o sentido e o significado para as pessoas" sobre o objeto de estudo.

Conforme Donato e Donato (2019) a revisão sistemática é dividida em 9 etapas:

a. Formular uma questão de investigação; b. Produzir um protocolo de investigação e efetuar o seu registro; c. Definir os critérios de inclusão e de exclusão; d. Desenvolver uma estratégia de pesquisa e pesquisar a literatura - encontrar os estudos; e. Seleção dos estudos; f. Avaliação da qualidade dos estudos; g. Extração dos dados; h. Síntese dos dados e avaliação da qualidade da evidência; i. Disseminação dos resultados - Publicação (p.228).

Todos estes passos têm de ser explicitamente descritos na revisão. A questão norteadora da pesquisa foi "quais os efeitos que a musicoterapia oferece no tratamento de idosos com Alzheimer?", após a qual foi estabelecido o protocolo de investigação. Como critérios de inclusão foram estabelecidos: a. Publicações nacionais e no idioma português (Brasil); b. Os publicados no período de 2015 a 2021; e c. Artigos de periódicos, trabalhos apresentados em eventos científicos e trabalhos acadêmicos. Como critérios de exclusão estabeleceram-se: a. as publicações incompletas; e b. Os trabalhos publicados em outras plataformas senão as selecionadas para o levantamento de dados.

Após definidos o protocolo e os critérios, foi realizado, pelos pesquisadores, o levantamento dos dados desta pesquisa nas plataformas científicas Scielo, Pepsic e Periódicos Capes, no período 1 a 30 de abril de 2021. No levantamento dos dados, para alinhar a investigação ao objetivo da pesquisa, foram utilizados os descritores: Alzheimer, idosos, velhos, música e musicoterapia.

Após a prévia seleção dos dados da pesquisa, foi iniciada a análise dos dados da pesquisa. A primeira etapa da análise foi a leitura de todos os títulos dos trabalhos selecionados, a fim de levantar os trabalhos em duplicidade e aqueles que, porventura, não tivessem relação direta com o tema desta pesquisa. Após essa primeira etapa obteve-se 65 publicações que foram para uma análise mais criteriosa. Nesta segunda etapa, foram avaliadas a qualidade das publicações. Os pesquisadores leram todos os resumos e sinopses das publicações, a fim de verificar se o conteúdo do trabalho correspondia aos interesses e objetivos desta pesquisa. A última etapa foi uma leitura interpretativa das publicações passaram pelos crivos anteriores. Nesta etapa os dados das publicações foram extraídos e lançados em quadros demonstrativos das ideias e interpretações dos autores quanto ao assunto em questão, os quais foram comparados, com o objetivo de estabelecer os pontos de concordância, distinção e discordância dos autores.

Após a realização da análise das publicações foram selecionados 31 (trinta e dois) artigos, 04 (quatro) dissertações, 03 (três) monografias e 05 (cinco) teses de doutorado, totalizando 44 (quarenta e quatro) produções com respaldo científico sendo essencialmente utilizados para a realização da revisão a seguir.

\section{Resultados e Discussão}

A fim de discutir a respeito dos aspectos que norteiam a doença de Alzheimer e a utilização da musicoterapia neste contexto, buscou-se através da literatura atender aos objetivos propostos por esta pesquisa, inicialmente abordando as 
características oriundas da doença de Alzheimer, discutindo a musicoterapia na saúde e posteriormente discutindo acerca do uso da musicoterapia aplicados em pacientes idosos diagnosticados com a doença.

\subsection{A doença de Alzheimer}

A doença de Alzheimer é caracterizada pela perda da massa cinzenta do cérebro em que, uma vez acometido pela doença, o indivíduo passa a apresentar significativas mudanças cognitivas, dentre elas a perda gradativa da memória. Trata-se de uma doença que compromete todo o funcionamento do organismo, uma vez que é considerada uma doença neurológica degenerativa, progressiva e que não tem cura (Fernandes \& Andrade, 2017). Caetano et al. (2017) comentam que essas doenças neurodegenerativas causam declínios irreversíveis no funcionamento de um indivíduo. Verifica-se, portanto, que a Doença de Alzheimer (DA) se configura como uma doença de desordem progressiva e crônica, ou seja, trata-se de uma doença que se desenvolve de forma lenta e de longa duração, normalmente acompanhando o sujeito durante toda a vida e causando a destruição dos neurônios colinérgicos (Machado, Carvalho \& Rocha Sobrinho, 2020).

As origens da doença de Alzheimer não foram até o dado momento definidas. Segundo Spezzia (2018) a etiologia dessa doença é desconhecida podendo, porém, ser influenciada por fatores tais como sexo, idade, doença cérebro vascular, traumas cerebrais gerados por quedas, tumores ou ainda ocupação profissional e grau de escolaridade. Rios Filho et al (2017) concordam que as causas da doença de Alzheimer não são bem esclarecidas, no entanto, comentam que sua causa pode estar relacionada a outros aspectos, tais como fatores genéticos e até mesmo a privação de sono, os quais comprometem o funcionamento e desempenho das sinapses. Com pensamento similar aos dois últimos autores, Monteiro (2018) reforça quanto a etiologia desconhecida da doença, mas infere que o Alzheimer pode estar ligada a uma "proteopatia", o que implica em uma anomalia envolvendo o enovelamento de proteínas no cérebro.

Entre as principais características da DA encontra-se o esquecimento. Aragão et al. (2018) e Monteiro (2018) comentam que nos estágios iniciais da DA é possível observar esquecimentos mais básicos relacionados a atividades diárias, posteriormente ocasionará uma ruptura da memória recente e nesse momento o indivíduo passa a desenvolver dificuldade em recordar-se de atividades realizadas há horas, até que no estágio final onde o indivíduo perde toda sua autonomia, não sabe mais falar, andar ou vestir-se sozinho, torna-se totalmente dependente. Os autores comentam ainda que, apesar de ser a principal característica, esquecer é apenas uma das muitas funções comprometidas. Gimenes (2019) comenta que as características advindas da DA, logo em seu primeiro estágio, podem ser facilmente confundidas com características atreladas à idade, o que tende a dificultar o prévio diagnóstico da doença.

O esquecimento é o sintoma mais característico do Alzheimer, no entanto, este antecede as demais perturbações advindas da doença, não demora para que a linguagem também seja afetada, tornando-se difícil inclusive dar os devidos nomes aos objetos. Essa diminuição na habilidade de falar pode possibilitar inclusive o desenvolvimento da apraxia e agnosia nesses pacientes. (Vieira, 2020). Além da afasia presente nesses casos, Cecato (2017) comenta sobre o deterioramento de determinadas áreas da cognição, tais como comprometimento da linguagem anteriormente citada, raciocínio abstrato e tomada de decisão desse paciente.

Apesar dos avanços tecnológicos e de pesquisas na área, até o momento, não foi possível identificar a cura para essa demência degenerativa que assola cerca de 60\% a 70\% dos idosos (Moreno et al., 2019). Por não ter cura, as estratégias no que tange o tratamento do Alzheimer se baseiam no retardo da sintomatologia da doença, evitando que a patologia se desenvolva mais rapidamente (Sequeira, 2020).

Por ainda ser um assunto pouco elucidado, o que se pode afirmar é que a DA é uma patologia progressiva e que com seu avanço, os aspectos funcionais dos pacientes vão entrando em declínio e se deteriorando. Para atuar de forma terapêutica e retardante dos sintomas, os quais surgem com o processo da doença, sugere-se o tratamento do Alzheimer em uma perspectiva 
psicossocial, terapia comportamental e tratamento farmacológico visando a melhoria da qualidade de vida do paciente (Diógenes et al., 2017). Vale citar que, Brotti et al. (2020) argumentam acerca do papel da psicologia como ponte facilitadora da qualidade de vida dos idosos acometidos pelo Alzheimer.

Os mesmos autores comentam que nessa perspectiva o profissional intervirá estimulando as habilidades cognitivas, buscará também o encorajamento do paciente no convívio social, visto que com a dificuldade de lembrar, falar e se comunicar, suas habilidades sociais também se tornam comprometidas. O profissional atribuirá atividades que tornem a vida desse idoso mais prazerosa e menos danosa frente a sintomatologia do Alzheimer. Por outro lado, Cruz, Mundin e Vieira (2018) sugerem a intervenção da terapia ocupacional, o que segundo as autoras, são capazes de promover a socialização, estimulação cognitiva, autonomia e independência desse paciente.

A saúde mental do idoso também sofre alterações em face dos sintomas negativos que surgem. Nesses casos, a psicoterapia é uma proposta plausível, entretanto, existem outras técnicas terapêuticas que podem ser empregadas e uma muito bem aceita entre os idosos é a musicoterapia.

\subsection{A musicoterapia na saúde}

A musicoterapia é uma ciência relativamente nova, embora a música seja utilizada há séculos como uma forma de oferecer satisfação e prazer as pessoas, seja ouvindo ou dançando. Barcellos (2015) argumenta que a música remonta de um período antigo e quando as pessoas a usavam tinham como principal objetivo a comunicação dos seres primitivos com divindades da época.

À época, esses seres se utilizavam principalmente da própria voz e corpo, imitando sons dos elementos da natureza, até que isso deixou de ser suficiente para se comunicarem e se expressarem. Então, sentiram a necessidade de criar instrumentos musicais que pudessem favorecer melhor sua comunicação com o seu habitat. Ulkowski et al. (2019) comentam que a música começou a ser usada como instrumento terapêutico durante a segunda guerra mundial, época em que os soldados feridos recebiam alguns músicos que ficavam tocando enquanto estavam sendo tratados.

Nesse momento, profissionais da área da saúde perceberam uma certa evolução na recuperação dos soldados, esse foi o marco inicial para que a musicoterapia bem como seus elementos como ritmo, altura, intensidade e timbre pudessem ser estudadas. Percebe-se, que a música percorre momentos diferentes da história, sendo usada de diversas formas, porém, com a finalidade de se expressar e se comunicar com o meio social.

Resende et al. (2017) afirmam que a música é posta como uma terapia complementar, denominada de musicoterapia, que se utiliza dos sons como ferramenta fundamental para estimular e despertar efeitos no ser humano. A musicoterapia é um processo sistemático de intervenção, em que o terapeuta ajuda o paciente se utilizando de experiências musicais e estabelecendo a relação terapêutica que é primordial (Sampaio et al., 2015). Apesar de trabalhar com música, Santos e Coronago (2017) ressaltam que a musicoterapia é uma terapia que se utiliza de sons, não só aqueles emitidos por instrumentos musicais, mas também de sons internos para trabalhar questões emocionais, psíquicas e sociais. Trata-se, portanto, de um processo ativo, no qual o paciente, de acordo com suas necessidades, características e habilidades individuais, participará de um processo terapêutico não convencional.

A musicoterapia influencia positivamente as capacidades motoras, de reconhecimento e de linguagem, além de trabalhar a memória autobiográfica que diz respeito a acontecimentos específicos da vida da pessoa. Essa memória evoca o sentido de identidade, de autoestima, de pertencimento e possibilita a expressão de sentimentos e emoções o que favorece vínculos familiares e sociais (Lopes et al., 2019). Sendo assim, o tratamento musicoterapêutico melhora a ansiedade, irritabilidade, agitação e humor desses pacientes. Ferreira et al. (2020) comentam que existe uma relação profunda com o 
processamento das emoções e evocação de memórias, por isso, a interação musical muitas vezes é a única possibilidade de comunicação com o paciente.

Como uma forma de instrumento, a música quando corretamente utilizada, se torna uma ferramenta poderosa que acende o cérebro para trabalhar a favor do indivíduo, onde diversas áreas são mobilizadas com o exercício da música e sendo transformado por ela (Rosado, 2019). Na proposta terapêutica, a música atua de forma a propor mudanças estruturais, funcionais e de padrões de conectividade. Palazzi (2015) comenta que a música atua de forma a alterar os padrões de conectividade, de forma a trabalhar na codificação e decodificação, sendo moldado de acordo com seu uso constante, trazendo benefícios para pacientes que têm essa área específica comprometida.

O uso da musicoterapia por profissionais visa a evocação da memória musical do paciente. Para isso, deve-se estabelecer um perfil do paciente, a fim de se levantar a sua história de vida e suas experiências musicais. Isso é obtido por meio de uma anamnese detalhada da história de vida desse sujeito. Sampaio et al. (2015) afirmam que é importante tentar reconstruir a história de vida desse indivíduo, trazendo esse paciente para o centro do seu tratamento. As lembranças trazidas pela música causam bem-estar ao paciente. A expressão desses indivíduos ao ouvirem uma música conhecida, associada com sua integração e a facilidade de comunicação que a música proporciona, demonstram as contribuições que a prática da musicoterapia pode oferecer no tratamento do Alzheirmer (Barbosa \& Cotta, 2017).

Pode-se afirmar, portanto, que a musicoterapia se utiliza da música e seus elementos de forma a construir técnicas, sendo elas realizadas geralmente por profissionais qualificados e treinados para ajudar esses pacientes (Torcate et al., 2020). É um processo de relação terapêutica, que os profissionais buscam de certa forma personalizar o atendimento de acordo com as necessidades de cada paciente. A respeito das técnicas de musicoterapia, Martins (2017) comenta que o objetivo é uma melhora na comunicação, que se expande às esferas sociais e cognitivas, sendo um tratamento não invasivo e de baixo custo, tornando-se muito eficaz na promoção e prevenção da saúde mental e física do paciente, podendo ser usada tanto na reabilitação quanto no tratamento.

Quanto a aplicação da musicoterapia é importante elucidar que a utilização da música se revela como uma fonte de intervenção potencial terapêutica. Neste sentido, Barbosa e Cotta (2017) compreendem que a musicoterapia é utilizada como um recurso terapêutico podendo ser considerada como uma terapia expressiva. Vale ressaltar que, a utilização da musicalidade como intervenção consiste em atribuir as vivências do sujeito e com a intervenção do terapeuta este processo se torna capaz de promover a melhora do paciente por meio da música. Mediante a utilização da musicoterapia como processo de mediação e intervenção considera-se importante apreciar os benefícios da utilização desse método terapêutico.

Resende et al. (2017) corroboram com a ideia de Babosa e Cotta ao comentar que de fato se trata de uma terapia expressiva e que, além disso, possibilita sensações prazerosas, as quais criam uma conexão com memórias do passado. Esta comunicação que a música estabelece com o indivíduo, de forma intrínseca e extrínseca, foi o que tornou a música uma aliada ao tratamento terapêutico do Alzheimer, pois quando associada a terapia, as músicas podem evocar canções familiares no indivíduo resgatando memórias mais profundas, ocasionando uma melhora da relação da pessoa com a própria mente e corpo.

\subsection{A musicoterapia no tratamento do Alzheimer em idosos}

A literatura é ainda muito escassa no que diz respeito as técnicas propriamente ditas e que são especificamente usadas no tratamento dos idosos com Alzheimer, sabe-se, sobretudo que a música é seu principal recurso e esse tipo de terapia estabelece-se em uma comunicação não verbal. No entanto, há dois tipos de técnicas que são utilizadas no processo de tratamento da musicoterapia com idosos, a esse respeito Miradouro (2015) e Santos e Coronago (2017) denominam como técnica ativa e recetiva. Na técnica ativa os idosos cantam, dançam ou usam instrumentos participando de forma ativa do processo, já na técnica recetiva o musicoterapeuta escolhe e utiliza uma música para realizar uma intervenção no tratamento. 
Técnica esta dividida em três momentos, que são de relaxamento, analítica e recetiva. A de relaxamento, como o nome sugere, busca aliviar as tensões, ansiedade e depressão desse idoso, a analítica é conduzida pelo profissional que escolhe uma música observando as emoções despertadas no paciente, e ainda recetiva que busca a recordação visando a ativação da memória associada a história de vida desse paciente.

A utilização da musicoterapia como recurso terapêutico em idosos acometidos pelo Alzheimer tem se mostrado, a partir das pesquisas levantadas, uma alternativa não invasiva, eficaz e de baixo custo, o que faz dela uma ótima alternativa de tratamento aplicada aos idosos que sofrem os danos da doença. A partir desta concepção, Anjos (2017) comenta que o uso da musicoterapia funciona como um agente terapêutico, pois mostra -se ser capaz de atuar nas dimensões não apenas psicológicas, mas ainda nas esferas físicas e sociais. Amancio (2019) e Leonardo (2017) argumentam ainda que dentre os diversos benefícios que a música se mostrou capaz de promover, pode-se citar a interação social por parte desse idoso dentro dos grupos em diferentes contextos em que ele possa estar inserido.

É importante salientar que dentre os sintomas do Alzheimer, a socialização torna-se totalmente comprometida, nesse sentido a música permite o processo de interação social, o que devolve a esse idoso o sentimento de pertencimento, juntamente com o resgate de seu eu, sua identidade e seu valor cultural, que serão possíveis ser acessados a partir da musicoterapia aplicada nesse contexto, propiciando a esse idoso uma melhor qualidade de vida.

Como ferramenta, a utilização da musicoterapia para os idosos acometidos pelo Alzheimer se torna uma forte aliada diante do percurso do tratamento, isso porque a musicoterapia permite ser possível estimular a afetividade, as emoções e as funções cognitivas. Conforme a contribuição teórica de Barbosa e Cotta (2017), os idosos com Alzheimer precisam ser estimulados tanto nos aspectos que envolvem a integralidade das dimensões biopsicossociais e espirituais como também em suas funções cognitivas. Nesse sentido, é possível confirmar através da literatura que a música serve como método e técnica de intervenção considerada eficaz no que tange o tratamento de idosos diagnosticados com Alzheimer.

Rocha et al. (2017) enfatizam que a musicoterapia como agente terapêutico no tratamento do Alzheimer é significativamente capaz de estimular e desempenhar um resgate da ativação das lembranças que o indivíduo possui, e essas memórias nesse contexto, são verdadeiramente importantes serem ativadas. Nesse mesmo sentido, Tinoco (2020) comenta que esses benefícios incidem com efeito a longo prazo, e além disso reforça o pensamento dos autores ao afirmar que a musicoterapia por meio da música trabalha principalmente nessa estimulação cognitiva do idoso que se torna capaz de recordar-se de músicas que fizeram parte de sua história de vida.

A aplicação da musicoterapia como tratamento da DA é considerada essencial porque age precisamente e ativamente na memória, efetivando principalmente as recordações consideradas valiosas na vida do idoso. Conforme as postulações teóricas de Martins (2017), a música é capaz de estimular as emoções e também os sentimentos de forma positiva proporcionando e ativando lembranças singelas e significativas. Além disso, quanto a sua aplicação, Rocha et al. (2017) comentam que a musicoterapia é capaz de melhorar gradativamente aspectos relacionados ao humor e consequentemente o comportamento do idoso.

O mesmo autor afirma ainda que o paciente tem papel ativo nesse processo, podendo inclusive escolher o ritmo ou a música em que devem trabalhar. Essas músicas ou ritmos ativam a memória musical que acabam por gerar benefícios, já que suas escolhas estarão ligadas a lembranças e memórias que envolvem a vida desse paciente propiciando mais uma vez uma significativa melhora em sua qualidade de vida.

As intervenções que a musicoterapia se mostrou capaz de proporcionar apresentam grande relevância no tratamento do Alzheimer. A esse respeito Martins (2017) comenta ser perceptível que a musicoterapia está sendo integrada e alinhada como forma de tratamento do Alzheimer. Com isso, tal recurso permite estabelecer o desenvolvimento do alívio da dor dos pacientes acometidos pela doença. Percebe-se, portanto, que a musicoterapia é eficaz na busca por qualidade de vida e retardo 
dos sintomas de perda de memória desses idosos, estimulando as emoções e ativando as memórias afetivas. Corroborando com o autor, Sobral, Araújo e Moura (2017) afirmam ainda que a música atua nas faculdades cognitivas ativando as emoções e a memória. Sobre este fato Martins e Quadro (2021, p. 05) complementam o pensamento dos autores ao colocar que "A música como agente terapêutico é entendida como possível porque a sensibilidade, a emoção, a percepção e a memória musical podem permanecer por mais tempo no cérebro do que as outras formas de memórias em um paciente com DA."

Quanto aos fatores que possibilitam essa ação da musicoterapia, Junior e Falcão (2017) comentam que a memória musical é uma das últimas a serem comprometidas com o avanço da doença de Alzheimer, dessa forma a estimulação cognitiva que é possível através da musicoterapia, acomete positivamente as regiões afetadas por estarem sendo estimuladas através da música, fazendo com que surja efeitos positivos na qualidade de vida desses idosos. Julio (2018) argumenta que a musicoterapia se torna uma intervenção de grande valor, isso porque as áreas afetadas pela doença se tornam o foco do tratamento a partir da música, reestruturando assim memórias que permaneciam até então esquecidas.

A musicoterapia com esses pacientes é possível porque a percepção, a sensibilidade, a emoção e a memória para a música podem sobreviver até muito mais tempo depois de todas as outras formas de memória terem desaparecido (...) para essas pessoas com demência, porém, a música pode ter efeitos mais duradouros - melhora do humor, do comportamento e até da função cognitiva, que persistem por horas ou dias depois de terem sido desencadeados pela música (Junior; Falcão, 2017, p. 31).

A partir das pesquisas levantadas é possível observar que os idosos que sofrem os danos da DA, por terem suas funções cognitivas comprometidas, tem como consequência suas habilidades motoras afetadas, o que resulta na diminuição de equilíbrio e considerável lentidão. Diante disso, Magalhães e Banhato (2019) afirmam a eficácia do tratamento com a musicoterapia a partir de imagens cerebrais obtidas durante seu uso. Os resultados apontam que, ao tocar as músicas preferidas de um determinado paciente, foi ativado em seu cérebro a área motora suplementar, que compreende a postura, além da ativação em conexões corticocorticais e corticocerebelares, responsáveis pela área sensorial e de atenção do idoso. Passos (2021) complementa que a partir de diversos estudos, a musicoterapia em idosos mostrou-se capaz de retardar o declínio cognitivo promovendo plasticidade no cérebro do idoso acometido pela doença de Alzheimer.

Dentro do que se foi exposto, fica claro que a musicoterapia tem potencial poder terapêutico aplicado nesse contexto. Em um estudo realizado no Japão, pacientes com DA eram submetidos a sessões de canto em um karaokê, seis meses de intervenção musical tiveram efeitos cognitivos surpreendentes, dentre eles uma melhora no Q.I, sono melhorado, maior ativação cerebral durante o cantar, e melhoras comportamentais significativas (Beltrame, Kihara \& Paschon, 2016).

Lopes et al. (2020, p. 5) enfatizam que a aplicação da musicoterapia aos idosos durante as sessões tem gerado comportamentos positivos, dentre eles os autores mencionam: "aumento do contato visual, expressões faciais e alterações positivas de humor que remetem a uma melhoria nas relações interpessoais." A esse respeito Beltrame, Kihara e Paschon (2016) comentam que, a música nesses casos é capaz de promover a liberação de endorfina, serotonina e dopamina e essas são substâncias responsáveis por reduzir a sintomatologia da doença, diminuindo a agressividade e depressão provenientes do Alzheimer, ativando ainda a motivação e recompensa no cérebro do idoso.

A doença de Alzheimer propicia aos idosos uma agitação comportamental considerável que pode ser devidamente explicada pelo declínio cognitivo oriundo da doença, a esse respeito, Carvalho (2018) comenta que dentre seus muitos benefícios, a música também atua reduzindo esses níveis de agitação verbal, vocal ou motora. Complementando essa afirmação, Nemes et al. (2017) enfatizam que a música enquanto intervenção terapêutica se mostra capaz de atuar em distúrbios comportamentais provenientes do Alzheimer, atua ainda na redução do estresse, estimulando a reabilitação da função cognitiva, preserva ou ainda resgata memórias gerando potencialmente uma melhor qualidade de vida a esses idosos. 


\section{Considerações Finais}

A partir das pesquisas realizadas na construção deste artigo foi possível compreender que a música faz parte da construção social e cultural dos indivíduos. A partir dessa relação do indivíduo com a música, as técnicas de musicoterapia tornam-se um valioso recurso de modalidade intervencionista relacionado ao tratamento de idosos acometidos pelo Alzheimer. A utilização da musicoterapia nesses casos possibilita um envolvimento por parte do idoso que a partir da experiência musical, se mostra capaz de expandir e ativar lembranças de sua história de vida, contribuindo para a qualidade de vida e no tratamento do idoso.

A música, como uma ferramenta da terapia, é capaz de aliviar o sofrimento diante dos sinais e sintomas da doença, uma vez que a sua utilização permite que o idoso crie uma nova perspectiva por meio da expressividade e do contato com suas emoções positivas, além de promover a plasticidade cerebral e retardar o declínio cognitivo.

Ressalta-se que no decorrer dos acessos as publicações sobre o tema, foi possível observar uma escassez de estudos voltados especificamente a utilização e efeitos do uso da música nesse contexto, fazendo-se necessários mais trabalhos direcionados a essa temática. Tendo em vista sua eficácia, os autores entendem se tratar de um assunto de grande significância, considerando o número de casos de idosos com Alzheimer no Brasil. Desta forma, entende-se, que devem ser realizados mais estudos sobre o tema a fim de termos novas possibilidades e maior conhecimento sobre a contribuições da musicoterapia. Necessita-se ainda o surgimento de políticas públicas capazes de fomentar pesquisas e aplicação da musicoterapia como produção de saúde e não somente no tratamento sintomatológico da doença de Alzheimer.

Tendo em vista os benefícios que o uso da musicoterapia revelou durante esse estudo, sugere-se que possa ser incluída como ferramenta nos tratamentos com pacientes diagnosticados com Alzheimer, pois seu uso acarreta em benefícios de uma forma não invasiva, de baixo custo, proporcionando ainda uma melhor qualidade de vida a esses idosos frente os sintomas da doença.

\section{Referências}

Anjos, A. G. et. al. (2017.) Musicoterapia como estratégia de intervenção psicológica com crianças: uma revisão da literatura. Rev. Interinst. Psicol. 10 (2), $228-238$.

Amancio, G. M. et al. (2019). A musicoterapia e suas contribuições para o fortalecimento da identidade e da cultura dos idosos institucionalizados na cidade de cajazeiras-pb. [trabalho de conclusão de curso]

Aragão, R. F. et al. (2018). As manifestações clínicas e implicações no cotidiano do idoso com doença de Alzheimer. Revista Interdisciplinar em Saúde, 5 (2), 198-207.

Barbosa, P. S., \& Cotta, M. (2017). Psicologia e musicoterapia no tratamento de idosos com demência de Alzheimer. Revista Brasileira de Ciências da Vida, 5 (3), 1-23.

Barcelos, V. M. et al. (2018). A musicoterapia em pacientes portadores de transtorno mental. Rev. enferm. UFPE on line, 12 (4), $1054-1059$.

Barcellos, L.R.M. (2015). Musicoterapia em medicina: uma tecnologia leve na promoção da saúde - a dança nas poltronas! Revista Música Hodie, Goiânia, 15 (2), 33-47.

Beltrame, G. R., Kihara, A. H. \& Paschon, V. (2016). Terapia musical aumenta a atividade psicomotora em pacientes com Alzheimer. 3 (6), 1-4 https://www.researchgate.net/publication/294276458_terapia_musical_aumenta_a_atividade_psicomotora_em_pacientes_com_alzheimer

Brotti, B. O. \& Vendrametto, D. C. (2020). Psicologia e Alzheimer: contribuições do psicólogo no tratamento de idosos. Revista Terra \& Cultura: Cadernos de Ensino e Pesquisa, 36 (70), 111-116.

Caetano, L. A. O., Silva, F. S. \& Silveira, C. A. B. (2017). Alzheimer, sintomas e grupos: uma revisão integrativa. Vínculo-Revista do NESME, 14 (2), 84-93.

Cruz, K. C. A., Mudin, T. L. D. \& Vieira, M. R. (2018) A intervenção da terapia ocupacional em pacientes com a doença de Alzheimer. Vita et Sanitas, 12 (2), $80-87$.

Carvalho, B. S. (2018). Efeitos da musicoterapia na agitação em idosos com demência: uma revisão sistemática. [Tese de Doutorado].

Diógenes, D. F. et al. (2017). Revisão da literatura acerca da conduta terapêutica na doença de Alzheimer. Mostra Interdisciplinar do curso de Enfermagem, 2 (1), 1-4. 
Donato, H., \& Donato, M. (2019). Etapas na Condução de uma Revisão Sistemática. Acta Médica Portuguesa, 32(3), $227-235$.

Da Luz, J. P. A. P., dos Santos Nunes, S., Anversa, E. T. R., \& Flores, G. C. (2021). A relação da depressão no idoso com a doença de Alzheimer: uma revisão da literatura. Brazilian Journal of Healh Review, 4(2), 9416-9429.

Fernandes, J. S. G. \& Andrade, M. S. (2017) Revisão da literatura acerca da conduta terapêutica na doença de Alzheimer: diagnostico, evolução e cuidados. Psicologia, saúde e doenças. 18 (1), 131-139.

Ferreira, M. F. A et al. (2020). Musicoterapia em pacientes com doença de Alzheimer-uma revisão sistemática. Revista Brasileira de Musicoterapia, XXII (28), 31-52

Rios Filho, E. G. R et al. (2017). Alzheimer: fatores de risco associados ao seu desenvolvimento e sua manifestação. In Resumos da XIII Mostra de saúde. (p. 33) Goiânia, GO.

Gil, A. C. et al. (2007) Como elaborar projetos de pesquisa. (4a ed.), Atlas.

Gimenes, F. F. (2019). Um probleminha de memória, um probleminha de cabeça, um probleminha de esquecimento: as estratégias referenciais em narrativas de um grupo de apoio. [Mestrado em linguística aplicada]

Gomes, A. S. \& Gomes, C. R. A (2020). Classificação dos tipos de pesquisa em Informática na Educação. In Jaques, P.A., Pimentel, M., Siqueira, S. \& Bittencourt, I.G.(Org.) Metodologia de Pesquisa em Informática na Educação: Concepção da Pesquisa. pp.1-33. Porto Alegre: SBC.

Junior, M. P. A. A. \& Falcão, D. V. S. (2017). Idosos com demência e seus cuidadores: uma revisão da literatura sobre os benefícios da musicoterapia. Revista brasileira de musicoterapia, 19, 251-256.

Júlio, P. J. (2018). Musicoterapia e demência: intervenção musicoterapêutica em idosos institucionalizados. 2018. [Dissertação de Mestrado].

Lopes, C. D. J. et al. (2019) Benefícios da musicoterapia no idoso com demência: revisão integrativa da literatura. Revista Investigação Enfermagem, 2(26), 45-59.

Lopes, G. K. et al. (2020). Capacidade funcional do idoso com demência de Alzheimer: O papel da musicoterapia. In Anais do VII Congresso medico Universitário de São Camilo. (p. 56-64).

Leonardo, A. M. M. (2017). O Ensino da Música e o Despertar das Emoções. [Doutorado].

Machado, A. P. R., Carvalho, I. O. \& Rocha Sobrinho, H. M. (2020). Neuroinflamação na doença de Alzheimer. Revista Brasileira Militar de Ciências, 6 (14), 30-38.

Magalhães, R. Z. \& Banhato, E. F. C. (2019). Musicoterapia para Idosos com Doença de Alzheimer: uma Revisão Integrativa. Cadernos de psicologia, 1 (1), 75-95.

Martins, H. P. \& Quadros, L. C. T. (2021). A música como Agente Terapêutico no Tratamento da Doença de Alzheimer. Psicologia em pesquisa, 15 (1), 1-21.

Martins, I. C. N. (2017) A música como Instrumento de Socialização: um estudo de caso sobre os benefícios da musicoterapia para a saúde e integração do idoso. [Trabalho de Conclusão de Curso]

Mendes, J. F. B. (2020) Musicoterapia em contexto hospitalar: a intervenção da musicoterapia em crianças com perturbação do espetro do autismo. [Dissertação de Mestrado].

Miradouro, J. C. S. (2015). Musicoterapia na doença de Alzheimer. [Tese de Doutorado].

Nemes, M. C. N. C et al. (2017) Revisão sistemática sobre intervenções com idosos na área da musicoterapia. Revista Brasileira de Musicoterapia, 19 (22), 48-78.

Monteiro, W. H. M (2018). Doença de Alzheimer: aspectos fisiopatológicos. Rev. Saberes, 8(2), 1-8.

Moreno. L. D. et al. (2019). Avaliação neuropsicológica em idosos com Alzheimer. In Anais do VI Congresso Internacional de Envelhecimento Humano. (p.16). João Pessoa, PB.

Vieira, M. M. C. D. S. (2020). A doença de Alzheimer e a perda de Olfato (Doctoral dissertation).

Passos, H. et al. (2021). A música como agente terapêutico no tratamento da Doença de Alzheimer. Revista Psicologia em Pesquisa, 15 (1), 1-22.

Palazzi, A. (2015). Musicoterapia na afasia de expressão: um estudo de caso. [Trabalho de Conclusão de Curso]

Resende, J. G. O. S., Carvalho, S. C. \& Santos, V. R. P. (2017) A utilização da musicoterapia para o paciente portador da doença de Alzheimer. Saberes Interdisciplinares, 7 (14), 69-80.

Ribeiro, E. A. (2008). A perspectiva da entrevista na investigação qualitativa. Evidência: olhares e pesquisa em saberes educacionais. Evidência, 4 (5), 129148.

Rocha, J. F. A da. et. al. (2017). A musicoterapia como alternativa terapêutica na assistência para pessoas com Alzheimer. Revista Querubim, 13 (ed especial), $1-8$.

Rosado, P. S. V. (2016). Na senda da neuroplasticidade: musicoterapia aplicada à reabilitação neurológica. [Dissertação de Mestrado]. 
Research, Society and Development, v. 10, n. 12, e112101220010, 2021

(CC BY 4.0) | ISSN 2525-3409 | DOI: http://dx.doi.org/10.33448/rsd-v10i12.20010

Sampaio, R. T., Loureiro, C. M. V. \& Gomes, C. M. A. (2015). A Musicoterapia e o Transtorno do Espectro do Autismo: uma abordagem informada pelas neurociências para a prática clínica. Per musi, 37 (1), 137-170.

Sacks, O. (2007). Alucinações musicais: relatos sobre a música e o cérebro. Companhia das Letras.

Smith, M. A. C. (1999). Doença de Alzheimer. Brazilian Journal of Psychiatry, 21(1), $03-07$.

Santos, F. R. \& Coronago, V. M. M. O. (2017). Uso da Musicoterapia como Terapia Alternativa no Tratamento da Doença de Parkinson. Revista Multidisciplinar e de Psicologia, 11 (35), 341-360.

Spezzia, S. (2018). Saúde bucal e doença de Alzheimer. Revista da Faculdade de Ciências Médicas de Sorocaba, 20 (4), 191-194.

Sequeira, J. A. (2020). Tratamento da Doença de Alzheimer: na atualidade e no futuro. [Tese de Doutorado].

Sobral, L. O. F., Araújo, L. C. A. \& Moura, T. A. O. (2017). Musicoterapia como tratamento sintomatológico da doença de Alzheimer: uma revisão integrativa. http://repositorio.asces.edu.br/bitstream/123456789/477/1/Alzheimer.pdf

Torcate, A. S. et al. (2020). Intervenções e Impactos da Musicoterapia no Contexto da Doença de Alzheimer: Uma Revisão de Literatura sob a Perspectiva da Computação Afetiva. In Anais do IV Simpósio de Inovação em Engenharia Biomédica-SABIO (p. 31). Recife, PE.

Tinoco, B. S. L (2020). Impacto Clínico de Intervenções com Música na Demência. [Tese de Doutorado].

Ulkowski, I. D. P. I., Cunha, R. R. S. \& Pinheiro, N. N. B. (2020). Da musicoterapia à musicoterapia orientada pela teoria psicanalítica: fundamentos epistemológicos. Revista InCantare, 10(1), 106-126. 